\title{
Are Rainfall and Temperature Really Changing? Farmer's Perceptions, Meteorological Data, and Policy Implications in the Tanzanian Semi-Arid Zone
}

\author{
Msafiri Y. Mkonda ${ }^{1,2, *}$ (D) and Xinhua $\mathrm{He}^{1,3, *}$ \\ 1 Centre of Excellence for Soil Biology, College of Resources and Environment, Southwest University, \\ Chongqing 400715, China \\ 2 Department of Physical Sciences, Faculty of Science, Sokoine University of Agriculture, \\ Morogoro 3038, Tanzania \\ 3 School of Biological Sciences, University of Western Australia, Crawley 6009, Australia \\ * Correspondence: msamkonda81@yahoo.co.uk (M.Y.M.); xinhua.he@uwa.edu.au (X.H.); \\ Tel.: +86-157-3009-3482 (M.Y.M.)
}

Received: 9 July 2017; Accepted: 8 August 2017; Published: 10 August 2017

\begin{abstract}
Although various climate models, statistical crop models and economic simulations have been established to determine the level of farmers' vulnerability, there has been little systematic assessment of farmers' perception towards climate change in association with meteorological analyses and policy implications in Tanzania. The results from this assessment will enhance the formation of robust policies that improve resilient livelihoods and the capacity to adapt to climate change and variability. This paper seeks to (i) reveal the farmers' perception on variation, change of rainfall, and temperature in the Tanzanian semi-arid area; (ii) depict meteorological evidence for the perceived rainfall and temperature changes; (iii) assess the policy perception and responses for the changing climate; and (iv) discuss the correlation between farmers' perception and meteorological data. Household surveys, informative interviews and discussions were employed during data collection. The Mann-Kendall Test and SPSS (version 20) were used for climate data analyses, while qualitative data were thematically analyzed. The results showed that from 1980 to 2015 the mean annual rainfall decreased $\left(R^{2}=0.21\right)$ while temperature increased $\left(R^{2}=0.30\right)$. Even though majority farmers agreed with these results, they had not yet taken serious measures to curb the situation. Besides, Agricultural Policy has lightly addressed and enforced the implementations of adaptation strategies to reduce climate impacts and vulnerability. Thereby, creation of awareness and intensification of climate adaptation strategies is needed at both farm and policy level.
\end{abstract}

Keywords: agricultural production; climate change adaptation; climate models; farmers' perception; government policies; semi-arid agro-ecological zones; vulnerability; Tanzania

\section{Introduction}

Climate change (CC) poses significant threats to agricultural production and adequate climate change information can help farmer to adapt to this [1,2]. This information is especially important in developing countries where agriculture is characterized by small holder and subsistence farmers [3]. Availability of accurate climate information will enhance the resilience among farmers to cope with the posed challenging conditions [4]. In addition, Paavola [5] observes that since climate change mostly affects vulnerable communities, there is a need to explore farmers' perceptions on climate change. Hereafter, actual perception on the same will be of use for improving agricultural production and environmental conservation in various agro-ecological zones. In addition, future precipitation projections from CMIP-3 and CMIP-5 models further suggest that towards the end of the 
twenty-first century, the eastern African region will experience inadequate wetter rainy seasons and thus, agriculture will be impacted negatively [6].

Most farmers perceive rainfall and temperatures as significant aspects of climate, since the two variables have profound and immediate impacts on their livelihoods and environment [3,7]. With them, the increase in drought extreme incidences is generally perceived as bad years. Several studies show that farmers can easily identify the changing climate through crop yields [4,8-10]. The prevalence of more bad years has negatively impacted farmers' livelihoods, thus affecting baseline vulnerabilities $[5,11]$. Despite the slight difference that may exist against the scientific point of view, the farmers' perception is rather reflected in the report by Intergovernmental Panel on Climate Change (IPCC) [12] that reveals that rainfall variations in terms of amount, frequency, inter-annual variability, onset, cessation or/and the shrinkage of the growing season are key indicators perceived by the farmers that climate is changing. Although the farmers' perception on climate change may differ between local and global levels, between communities and between climatic regions [7,13], Paavola [5] and Kilembe et al. [14] point out that farmers' perception are crucial when proposing adaptation plans or mitigation measures that would help farmers to cope or/and decrease their vulnerability to such environmental stresses.

So far, there is substantial literature examining the effects of climate change in Tanzania. Studies by Ahmed et al. [4], Rowhani et al. [8], Lobell and Burke [15], and Lobell et al. [16] are among the dominant studies that established climate knowledge based on climate models, statistical crop models, and economic simulations to determine climate vulnerability among the smallholder farmers between the late 20th century and early 21st century. Rowhani et al. [8] specified that a 20\% increase in intra-seasonal precipitation variability reduces agricultural yields by $4.2 \%, 7.2 \%$, and $7.6 \%$ for maize, sorghum, and rice respectively, which are the major food crops in Tanzania. The study further projected that by 2050 climate change and variability will stress crop yields in Tanzania by $3.6 \%, 8.9 \%$, and $28.6 \%$ for maize, sorghum, and rice respectively. These studies with others such as Paavola [5] Mongi et al. [10], Kilembe et al. [14], Lobell et al. [16], Msongaleli et al. [17], and Mkonda [18] confirmed the decreasing rainfall in various parts of Tanzania, and insisted that this scenario has significant implications to crop yields. This was further supported in recent studies by Below et al. [7], Sieber et al. [13], FAO [19], Kangalawe [20] and Cooper and Wheeler [21].

In addition, Lobell et al. [16], and the Food and Agricultural Organization of the United Nations [19] further emphasized that rain-fed agriculture will be more susceptible to any further variation in climate. Similarly, Challinor et al. [1] established that climate change and variability has significantly affected staple food crops especially cereals like maize, rice, sorghum and millet. In addition, Challinor et al. [1], Adger [3], Paavola [5], Kangalawe [20], and Kangalawe and Lyimo [21] assert that the increase in drought incidences has increased the level of vulnerability among the farmers in most sub-Sahara Africa because their livelihoods depend entirely on rain-fed agriculture. Spatially, this vulnerability is more pronounced in semi-arid areas because of prolonged excessive droughts being mainly attributed to unreliable and erratic rainfall, very low mean annual rainfall, and quite unpredictable onset and cessation rains [1,14,22-36].

In terms of policy reflection, the National Adaptation Plan of Action and Tanzania's National Strategy for Growth and Reduction of Poverty identified droughts and floods as among the primary threats to agricultural productivity and poverty vulnerability in the country [23-25]. According to Tanzanian context, climate change issues are addressed in various sectoral policies i.e., all ministries related to environment have policies that address the same. Among others are the Agriculture and Livestock Policy of 2013, National Environmental Policy of 1997, National Forestry Policy of 1998, National Tourism Policy of 1999, and the Agricultural Sector Development Program of 2002 [26]. However, our interest is in the Agricultural Sector which is a lead Ministry in this category [23].

Tanzania agricultural policy aims at increasing food security levels in the country through increased crop production [23]. In response to climate change, the policy has emphasized the use of drought resistant crops, increased irrigation and soil fertilization, but this has not yet been fruitful. It actually realizes that rainfed agriculture is no longer a good proposition for crop production in the 
country. In this regard, different adaptation strategies such as early farming, planting short maturing crops, and diversification to other economic sectors have been equally estipulate in the policy. On the other hand, the policy attracts large scale investment (intensive agriculture) in agriculture to maximize the production levels and curb food insecurity in various agro-ecological zones of the country.

The agricultural sector in Tanzania is a spearhead economic sector in the country (serving over 70\% livelihoods), thus the policy has taken some precautions that reduce the vulnerability of smallholder farmers from climate change impacts. For collective implementations, the government introduced a number of initiatives and programs to spearhead the agriculture sector. The Agriculture Sector Development Program (ASDP) was introduced in the 2000s to speed up crop production in the country. Similarly, the "Kilimo Kwanza" (Agriculture First in English) initiative which was introduced in 2009, aimed to hasten the production of the agricultural sector and its allied sectors. The ASDP aims to enable farmers to have better access to and use of agricultural knowledge, technologies, and market infrastructure; all of these contribute to higher productivity, profitability, and farm incomes within the era of a changing climate, under a Local Level Component and a National Level Component. It is mainly implemented by Local Government Authorities based on District Agricultural Development Plans as part of the broader District Development Plans. Thereby, the initiatives and programs are there to facilitate the achievement of the Tanzania Development Vision of 2025, especially in this era of global climate change [26,27].

Since farmers' perceptions are mainly based on the impacts of CC on their livelihoods, this study has also touched on the major adaptation strategies adopted by the farmers in the process of reducing their vulnerability to CC $[23-25,36]$. The existing adaptation strategies may inform much about the farmers' knowledge on these adaptation strategies. In general, the adoption of climate smart-agriculture (CSA) practices is highly recommended by various studies as an adaptation strategy to CC impacts [20-24]. The CSA includes, but is limited to, conservation agriculture, irrigation, and the use of drought resistant crop cultivars [32-35]. Kimaro et al. [31] recommends the use of CSA practices as a strategy to optimize yields under the auspice of climate stress along the Eastern Arc Mountains of Tanzania; however, most of these practices have not yet met the required demand of farmers in the area, thus far, much efforts should be done to make CSA beneficial and sustainable from local to national level.

Although the science of detecting, attributing changes in the climate impacts and developing projections for future changes is progressing rapidly, there has been little systematic evaluation of farmers' perception to climate change as associated with meteorological analyses and policy implications in Tanzania. The establishment of this aspect will be a robust step to building resilient livelihoods, an adaptive capacity for climate change, and variability through the adoption of climate smart agriculture that is endorsed by sound policies and tools. Thus, it was worthwhile to ascertain climate information basing on farmers' perception and experiences (indigenous knowledge), meteorological data and assess the policy responses for the benefits to farmers.

The main impetus of this empirical study was to assess farmers' perception on climate change in the Kongwa District, the semi-arid area of Central Tanzania, analyze rainfall and temperature data from Tanzania Meteorological Station (TMA) and meteorological stations in the study area e.g., Kinyasungwe meteorological station, and finally, assess policy implications on the same.

\section{Materials and Methods}

\subsection{Profile of the Study Site}

The study was carried out between June and September 2016 in Kongwa District, Dodoma Region, located in the semiarid zone of Tanzania. The District is located between latitude $5^{\circ} 30^{\prime}$ to $6^{\circ} 0^{\prime} \mathrm{S}$ and longitude $36^{\circ} 15^{\prime}$ to $36^{\circ} \mathrm{E}$ with an area of about $4041 \mathrm{~km}^{2}$. Mnyakongo and Ugogoni villages were sampled for this study (Figure 1). The current population of Kongwa District is estimated to be 318,995. This population grows at a growth rate of $2.4 \%$ per annum. The number of households is 60,301 with 
an average size of 4.9 persons. The number of farming households is 45,271 , which are almost equal to $90 \%$ of the total households.

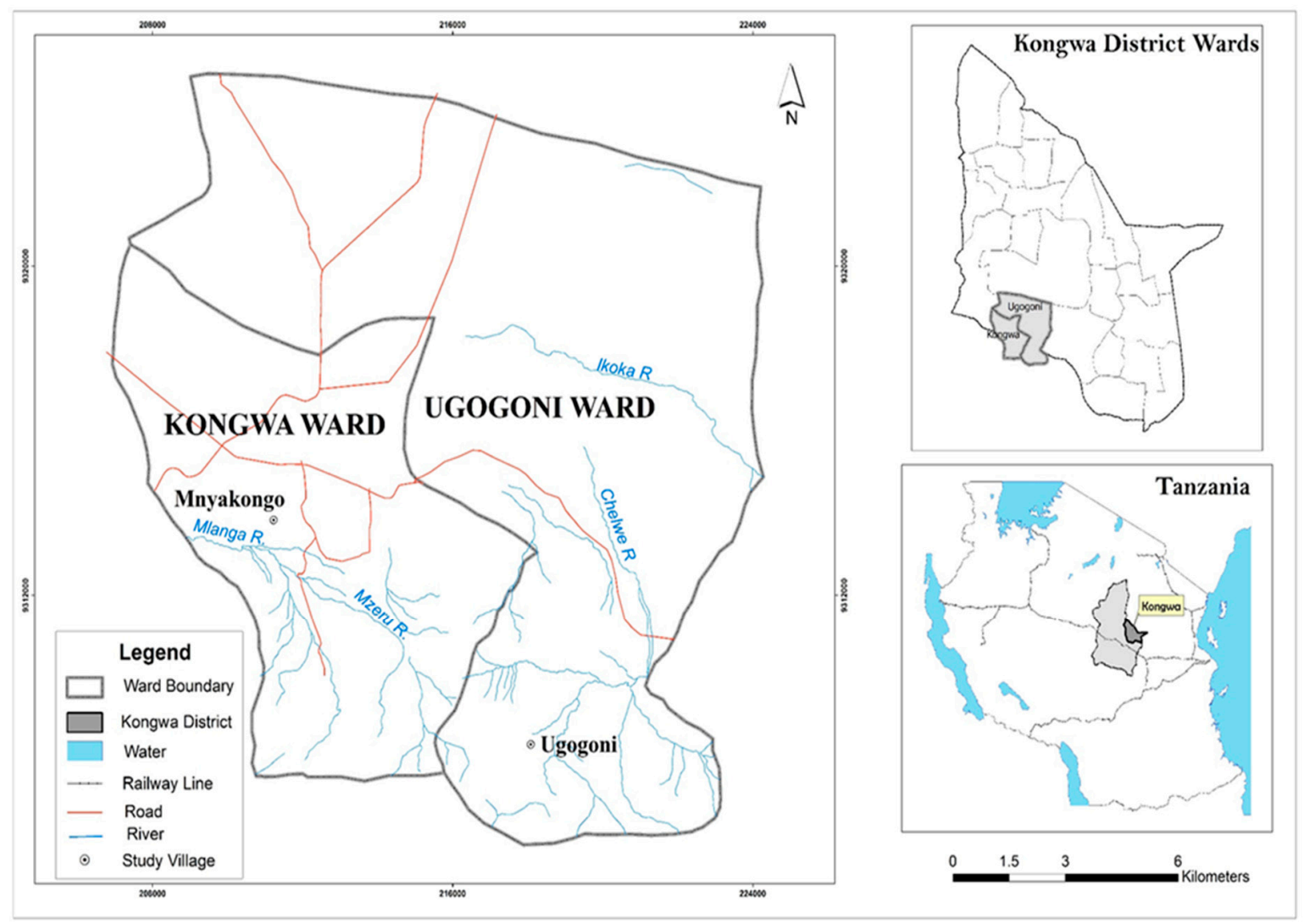

Figure 1. The Study Area.

\subsection{Biophysical Characteristics of the Study Area}

The elevation of the district ranges from 900 to 1000 meters above sea level. The district is on the leeward side of Ukaguru Mountains. It has a total annual rainfall ranging from 400 to $600 \mathrm{~mm}$, while in the southern part it ranges from 600 to $800 \mathrm{~mm}$. The mean annual rainfall in the area is about $500 \mathrm{~mm}$, which is not enough to ensure crops production. The rainfall pattern is bi-modal with short rains commencing November to December, and long rains falling from January to mid-April. The annual temperature of the area varies from a mean minimum of $18^{\circ} \mathrm{C}$, to a maximum of $34^{\circ} \mathrm{C}$. Erratic and unreliable rainfall, prolonged dry spells, and increasing incidences of peak temperature are the dominant weather pattern in the area [8].

\subsection{Data Collection}

Field data collection was conducted from June to September in the study area. Different research methods were employed to collect both quantitative and qualitative data from primary and secondary sources. The sampling unit for this research was a household (Table 1).

Table 1. Respondent profiles.

\begin{tabular}{ccccc}
\hline Region & District & Village & Total Households & Respondents \\
\hline Dodoma & Kongwa & Mnyakongo & 2050 & 200 \\
& & Ugogoni & 2080 & 200 \\
\hline
\end{tabular}

Source: Field Survey Data, 2016. 
Purposive sampling was employed to select the study area (a district that had often experienced food insecurity), while simple random sampling was used to select the villages [23-25]. Household surveys, informative interviews, physical observations, group discussions, and literature reviews were employed for data collection and crosschecking to grasp information on onset, cessation and duration of the growing season, while key informant interviews with agriculture and environmental experts were held to obtain a formal overview on the same.

We conducted household surveys using both structured and semi-structured questionnaires in which about $10 \%$ of the village households were sampled. A total of 400 farmers were randomly sampled to respond the questions from questionnaires where each village, i.e. Mnyakongo and Ugogoni, involved 200 respondents. To ensure that random sampling was representative; we used the list of households from the 10 cell leaders to randomly sample ten percent of total households by randomly 'tick' marking a few households. In each household, the key respondent was the head of that household $(\mathrm{HH})$. In areas where $\mathrm{HH}$ were more knowledgeable, we conducted more detailed interviews with them on the same. This aimed to acquire extra answers from them based on their expertise and experience. These HH partly included retired agricultural officers and the related professions together with a few learned people in the area. We used household units to collect data related to climate change and variability to acquire multiple perceptions and their implications. First, preliminary questions were aimed at exploring their general understanding toward climate change and the level of confidence to talk about integrating adaptation and mitigation in their farming activities.

We also asked them to give specific examples of adaptation and mitigation practices that are implemented in their locality. Second, we asked questions on whether the governing policy gave any guidelines about the integration of adaptation and mitigation (i.e., climate smart) in their farming. Third, through open-ended and non-prescriptive questions, we asked them to describe how they perceived the benefits, risks and barriers of integrating adaptation and mitigation in farming practices, and what were their future prospects, given that climate will continue changing.

Meanwhile, rainfall and temperature data from 1980 to 2015 were collected from the Tanzania Meteorological Agency (TMA) and meteorological station (Kinyasungwe) within the study area. The data from these sources were authentic and reliable for providing a required quantum that could inform a robust analysis of results.

\subsection{Data Analyses}

Quantitative data from the questionnaire were coded, processed, and analyzed descriptively using Statistical Package for Social Science (SPSS) (version 20). Rainfall and temperature data basing on annual and monthly variability from 1980-2015 were analyzed using the Mann-Kendall Test and Microsoft excel (window 13) to establish the temporal variability. In addition, the numbers of wet spells during the growing season (i.e., January, February and March) were also determined. This was particular important, because the number of wet and dry spells are good indicators of rainfall variability and thus, they have significant impacts on crop yield. Qualitative data were analyzed through the theme content method, and the narratives were inserted in the discussion.

\section{Results}

The results of this study focused on the perceptions of farmers, results from meteorological data analyses and policy implications to climate change aspects. The discussion was conducted based on these variables to enable policy makers and other agricultural practitioners to propose sound agricultural policy that can strengthen climate smart agriculture from the district to the national level.

\subsection{Characteristics of the Respondents}

It was somewhat important to understand the characteristics of the respondents (Figure 2a,b). Age, sex, and level of education had significant impacts to the responses of research questions. 
Other demographic characteristics such as religion, ethnicity, health statuses, etc., were not presented because firstly, they had no significant contribution to the knowledge and experiences on climate change, and secondly, the Constitution of Tanzania discourages the interrogation of issues related to religion, ethnicity and health unless the person him/herself reveals them willingly. This is purposely done to maintain unity and peace among the people. Thus, education, age and sex were sufficient.

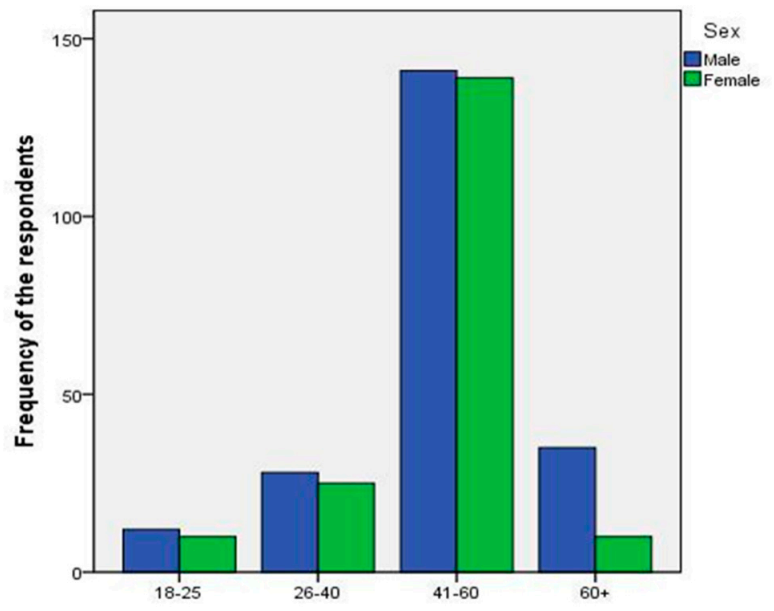

(a)

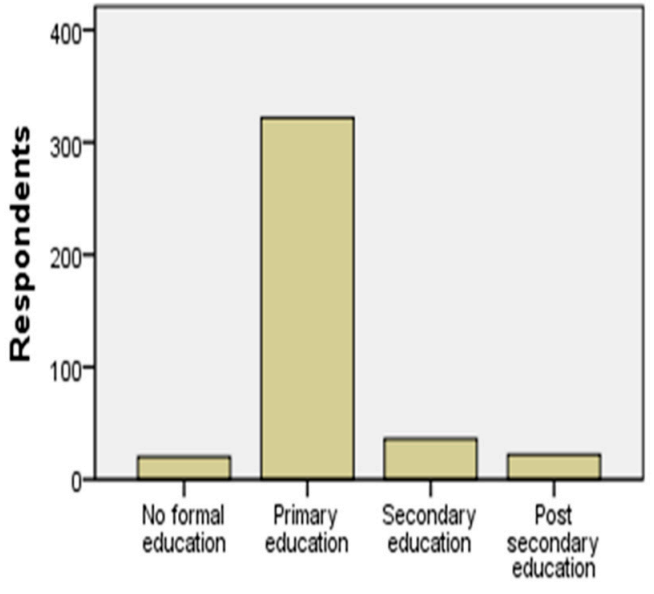

(b)

Figure 2. (a) Age and sex of the respondents. Source: Field Survey Data; (b) Age and sex of the respondents. Source: Field Survey Data.

\subsection{Farmers' Perceptions on Temperature and Rainfall}

\subsubsection{Overall Perception}

Farmers' perceptions on whether temperature and rainfall were changing was expressed in numerous ways. We assessed the perception of the farmers towards the major aspect of climate on the basis of time. The farmers expressed their understanding basing on annual and/or growing season. In identifying the main aspects of weather, $50 \%$ mentioned rainfall as the dominating aspect, while $25 \%, 20 \%$, and $5 \%$ identified temperature, sunshine, and humidity respectively (Figure 3 ).

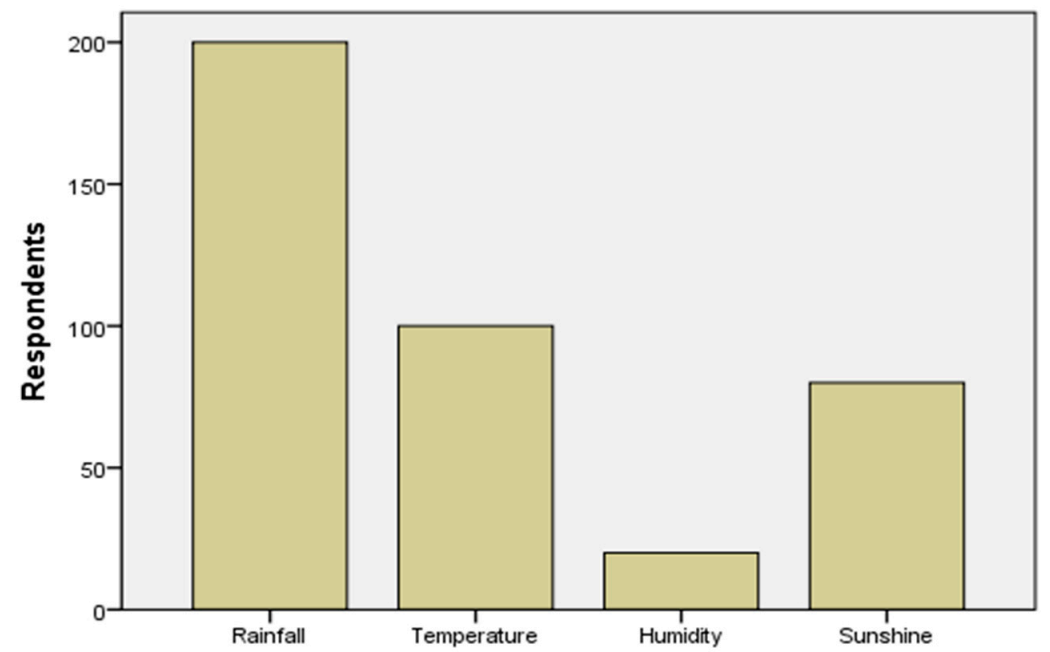

Figure 3. Overall perception of farmers toward the major climate aspects. Source: Field Survey Data. 
Overall understanding indicated that about $60 \%$ of the farmers asserted that temperature was increasing, while $30 \%, 7 \%$, and $3 \%$ assumed that it has been fluctuating, decreasing, and no change, respectively (Figure 4).

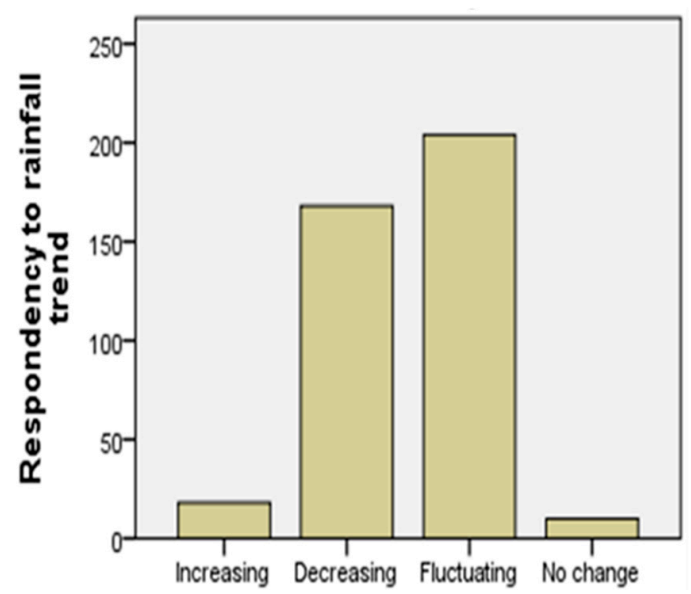

(a)

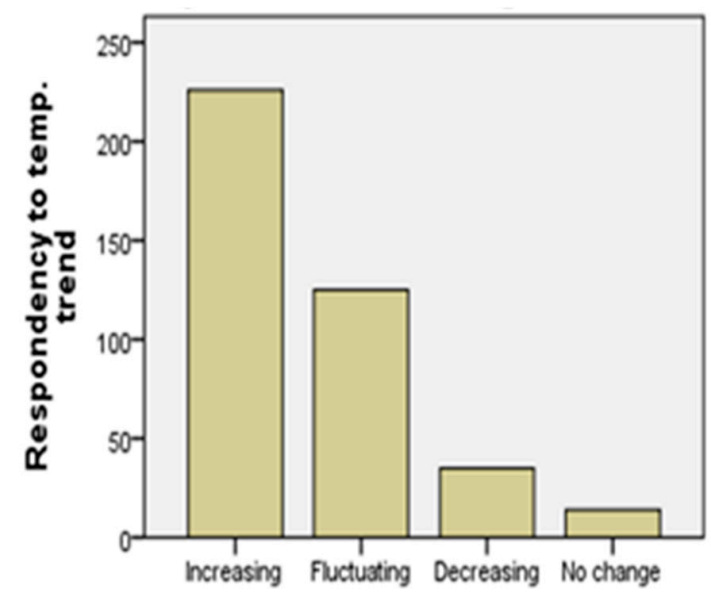

(b)

Figure 4. Overall perception of farmers on the trend of rainfall (a) and temperature (b). Source: Field Survey Data.

\subsubsection{Specific Perceptions during the Growing Season}

To elicit specific perceptions, we addressed specific questions that could determine the reuired knowledge. Since the area has a single growing season starting in January to April, we had great interest in focusing on this period (Table 2). In this aspect, most answers were more direct than those we obtained for general perception.

Table 2. Farmers' perception on temperature and rainfall changes during the growing season.

\begin{tabular}{|c|c|}
\hline Variable & Percent of Respondents \\
\hline \multicolumn{2}{|l|}{ (a) Temperature } \\
\hline Temperature increased & 80 \\
\hline Temperature decreased & 8 \\
\hline Temperature stayed the same & 12 \\
\hline \multicolumn{2}{|l|}{ (b) Rainfall } \\
\hline Rainfall increased & 15 \\
\hline Rainfall decreased & 60 \\
\hline Rainfall stayed the same & 25 \\
\hline Number of respondents & 400 \\
\hline
\end{tabular}

In all cases, the responses in Table 2 above imply that many farmers $(80 \%)$ perceived that temperature has been significantly increasing, while rainfall has mostly been decreasing $(60 \%)$, and sometimes remaining the same $(25 \%)$.

\subsection{Results from Meteorological Data Analyses}

\subsubsection{Rainfall}

The findings in Figure 5 show that, the mean annual rainfall patterns from 1980 to 2015 were observed to decrease at a non-significant rate of $R^{2}=0.21$. This annual rainfall pattern displayed a wider context on long-term variability that explored the general situation on the ground $[1,18]$. In addition, 
the mean monthly rainfall during the growing season i.e., January, February and March had been decreasing at a non-significant rate of $\mathrm{R}^{2}=0.0911,0.008$, and 0.0061 respectively (Figures 5 and 6). Similarly, the number of wet spells decreased significantly at $R^{2}=0.2977,0.1837$, and 0.2878 on the same monthly basis (Figure 6). Further, the analyses of the intra-climatic variation during the growing season (i.e., January, February and March) indicate that; January had the most fluctuating rainfall trend compared to February and March (Figure 5a).

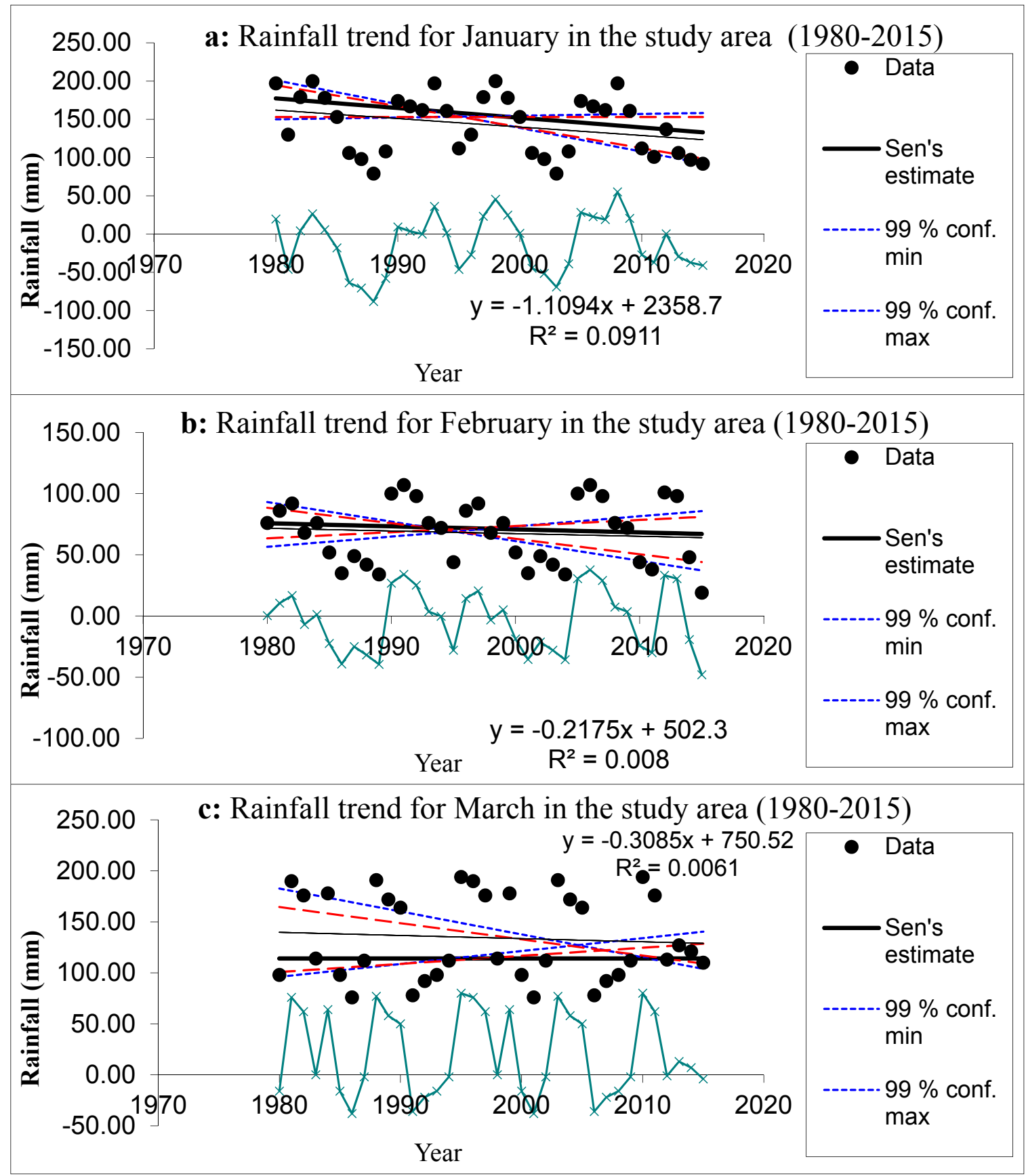

Figure 5. Trend of mean monthly rainfall for January (a); February (b) and March (c). Source: Field Survey Data, 2016.

To ascertain actual farmers' perceptions on climate at a farm level, we further analyzed the wet spells. These are the number of days that received rainfall in a particular month. For the past 35 years the number of wet spells has significantly fluctuated at the decreasing trend at $R^{2}=0.2977$ (January), 
$\mathrm{R}^{2}=0.1837$ (February), and $\mathrm{R}^{2}=0.2878$ (March). Despite having the highest wet spells (18 maximum and eight minimum) in February and March (Figure 6b,c), January had optimal variability of wet spells compared to its counterparts (5a).

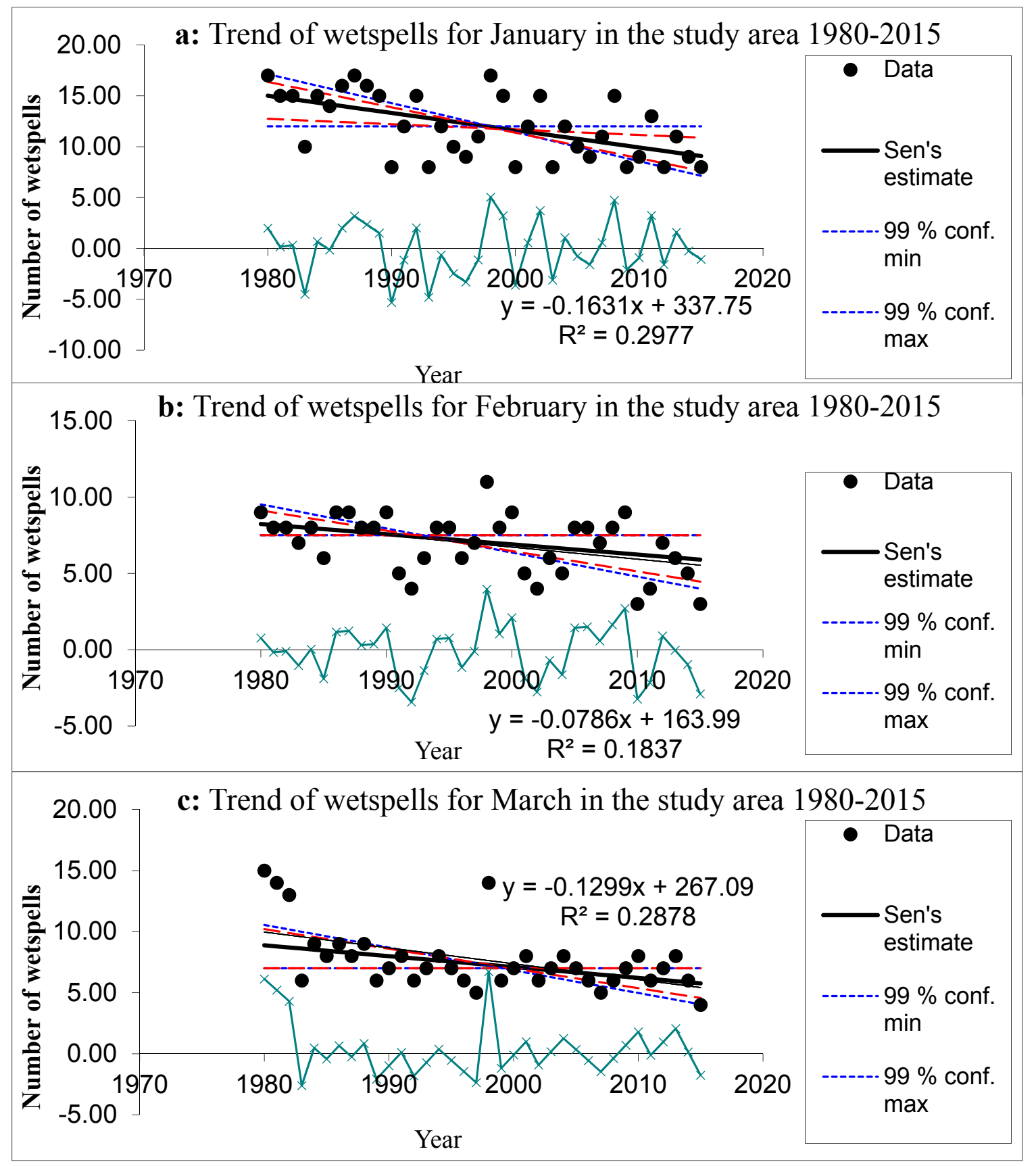

Figure 6. Number of wet spells for January (a), February (b) and March (c). Source: Field Survey Data, 2016.

\subsubsection{Temperature}

The mean annual temperature patterns increased significantly at the rate of $R^{2}=0.30$ while those of January, February, and March increased significantly at $R^{2}=0.15,0.07$, and 0.22 respectively (Figure 7). This particular trend reflects what happens in global temperature scenarios, as presented in various climate models $[6,12]$. 

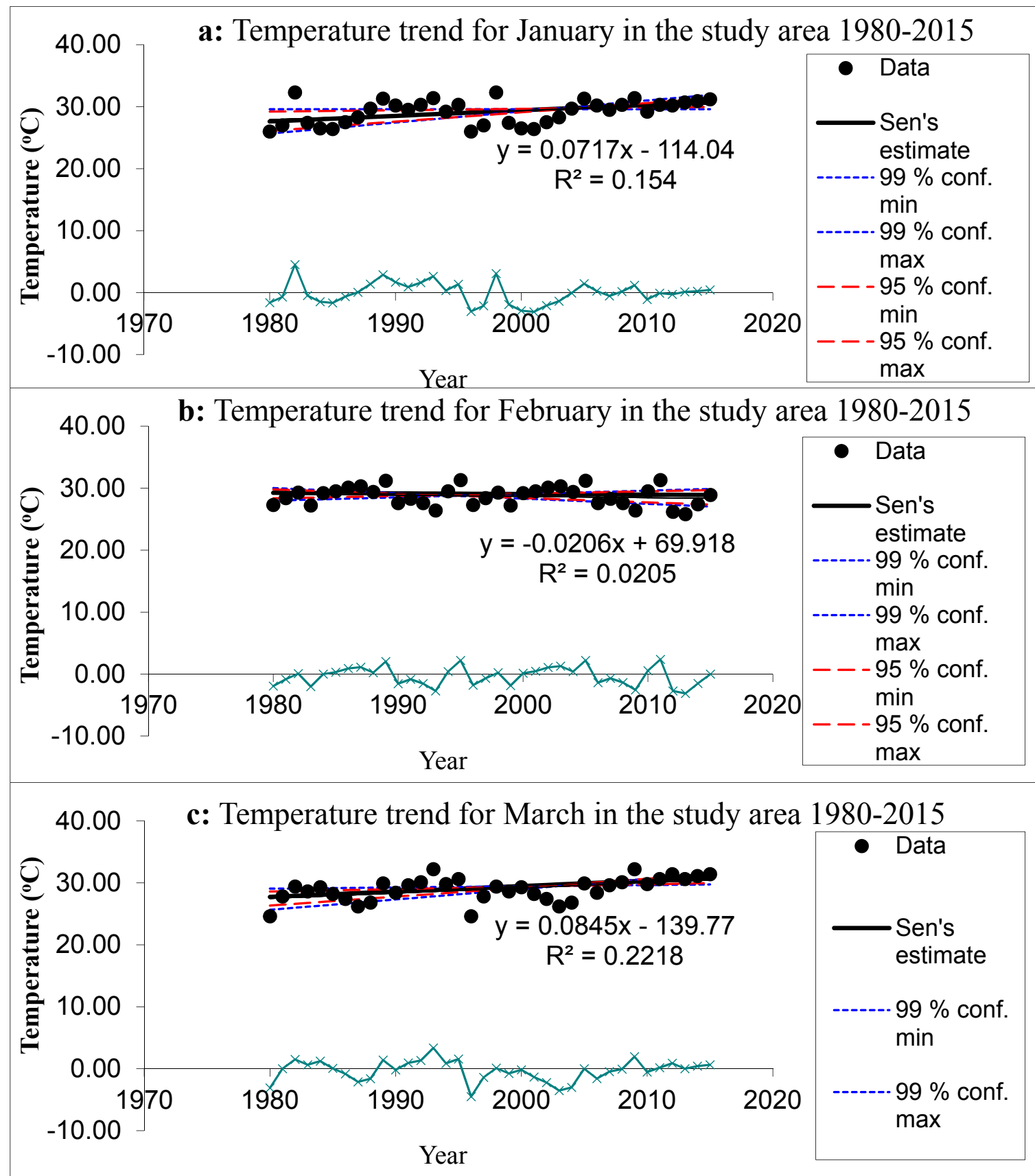

Figure 7. The mean monthly temperature Trend for January (a); February (b) and March (c). Source: Field Survey Data, 2016.

\subsection{Community-Based Adaptation Measures to Climate Change Impacts}

Being in a semiarid area, the communities in Kongwa District have adjusted to the changing climate through adopting certain measures. The farmers asserted that they had been responding to climate impacts in a number of ways. The results in Table 3 represent a wide range of climate smart agriculture practices in the area, as a strategy to reduce the vulnerability, whereas $70 \%$ of farmers in Mnyakongo village appeared to be aware of the timely farming operation, while $52 \%, 47 \%$, and $35 \%$ paid much attention to early planting, little tillage, and mulching, respectively. The same pattern was reflected in Ugogoni village at 51\%, 37\%, 35\%, and 43\% respectively (Table 3). These adaptation strategies were not only adopted in Kongwa District but also most of these were reported to be adopted 
in other regions of the country [10]. However, despite the adoption of these adaptation strategies, it appeared that the vulnerability of the majority of rural farmers was still high.

Table 3. Farmers' adaptation strategies to drought conditions in the study area (in \%).

\begin{tabular}{cccc}
\hline Adaptation Activities & Mnyakongo $\mathbf{( N = 2 0 0 )}$ & Ugogoni $(\mathbf{N}=\mathbf{2 0 0})$ & Total $(\mathbf{N}=\mathbf{4 0 0})$ \\
\hline Timing of farm operations e.g., planting & 70 & 51 & 60.5 \\
Planting early maturing varieties & 52 & 37 & 44.5 \\
Little tillage & 47 & 35 & 41.0 \\
Mulching & 35 & 43 & 39.0 \\
Agroforestry & 23 & 25 & 24.0 \\
Plating high yielding varieties & 17 & 14 & 15.5 \\
Practicing crop rotation & 10 & 6 & 8.0 \\
Small-scale irrigation & 9 & 4 & 6.5 \\
\hline
\end{tabular}

Source: Field Data Survey, 2016.

In addition, the study found out that although the majority of the farmers were not responsive to policy issues, few farmers $(>50 \%)$ were aware that the governing policy emphasized climate smart agriculture to overcome the drought. Similarly, the study discovered that economic stringency was the major reason for farmers to optimize their adaptive capacity, however they anticipated they would learn more technological strategies, especially the expansion of irrigation to overcome the changing climate. In this aspect, they suggested that the government did not do enough to make agriculture a developed and sustainable sector (Table 4).

Table 4. Farmers' suggestions to the government in improving climate resilience (in \%).

\begin{tabular}{cccc}
\hline Adaptation Activities & Mnyakongo (N = 200) & Ugogoni (N = 200) & Total (N = 400) \\
\hline Great supply of drought resistant crops and cultivars & 60 & 51 & 55.5 \\
Heavy investment in irrigation technologies & 72 & 77 & 74.5 \\
Strengthening Rain Water Harvest technology & 70 & 65 & 70 \\
Emphasis on organic fertilization & 80 & 70 & 75 \\
To maximize crop production during good years & 72 & 74 & 73 \\
Emphasis on transformative climate adaptation & 60 & 64 & 57 \\
Agricultural Policy should address the current challenge & 57 & 55 & 60 \\
The government should put a direct hand in agriculture & 60 & 83 & 80 \\
Increased government's willingness to address climate impacts & 77 & &
\end{tabular}

Source: Field Data Survey, 2016.

\section{Discussion}

The present study has confirmed that real rainfall and temperature are changing. The results in Figure 3 shows that more than $50 \%$ of the respondents mentioned rainfall as the main aspect of climate, exceeding temperature, sunshine, and humidity respectively. This reflects how rainfall variability is understood and affects people's livelihoods in the area. Rainfall variability has been affecting the onset and cessation, thus upsetting the farming calendar in the area. The results from meteorological data analyses and farmers' perception with regards to policy review supports this assertion (Figures 2-7, and Tables 2 and 3). The farmers' responses in Figures 2-4 indicated the farmers' awareness on the changing climate and more especially on the increasing frequency of droughts extremes in the area.

Besides, the results showed that $60 \%$ of the farmers were assertive that the mean annual temperature has been increasing, while 30\%, $7 \%$, and 3\% assumed that it has been fluctuating, decreasing, and no change respectively (Figure 4), while 80\% said that the mean temperature during the growing season has been increasing (Table 2). This response was related to the changes in temperature on annual basis. They also confirmed that rainfall has generally been decreasing. These results were in agreement with Ahmed et al. [4], Below et al. [7] and Rowhani et al. [8]. They additionally argued that rain onset and cessation have been too unpredictable, which have been affecting their farming 
calendar. They also reported that, in the recent years, there has been shrinkage of long rains which used to appear from around November to April, but now prevailing from around January to March. This has posed significant impacts to the major livelihoods of the people.

Further, the farmers noticed that the overall climate has been changing, even though they did not give any quantification of the change (Figure 4). These climatic turbulences disturbed the agricultural systems, ecology and ecosystems of the area. About $60 \%$ of the respondents who asserted rains to have been decreasing during the growing season, also informed that there have been increased incidences of droughts extremes. This verdict is in agreement with Ahmed et al. [4], Below et al. [7], and Rowhani et al. [8] who found that more than $50 \%$ of the respondents asserted on decreasing rains. Despite the increasing change of farming systems and less dependence on farming, most rural people in Tanzania and Africa are still vulnerable to climate change $[13,36]$. To reduce the vulnerability, farmers have been adopting some adaptation measures like early planting and planting drought tolerant crops to adjust to the stress; however, the level of rural peoples' vulnerability is considerably high. Consequently, by stipulating in the policies that climate change impacts should be adapted, agricultural and other sectoral policies have adhered to the reality that climate is changing $[24,25]$.

In Ugogoni village, the farmers asserted that for the past ten years there has been an increased shrinkage of the growing season. They further clarified that formerly the growing season had about five months commencing from December to April, but in recent times, this duration had decreased to three or two months. This shrinkage has confirmed the disappearance of short rains which previously used to appear around October to December. Meanwhile, the farmers in Mnyakongo village acknowledged that in some years there had been high rainfall; however with fewer wet spells and thus far, bringing little crop yield. This was in agreement with meteorological analyses where high rainfall can be recorded but with either fewer or unevenly distributed wet spells (Figure 6). In most cases, the area had been receiving fewer wet spells that were insufficient for agricultural production.

Given that smallholder farming is the most vulnerable livelihood in the area and most of sub-Saharan Africa [2], to reduce this vulnerability, Paavola [5] and Sovacool et al. [11] accentuate that local adaption strategies such as early planting should be emphasized by agricultural and extension officers, in order to increase resilience and quick recovery from climate change impacts. These officers are responsible for the planning and implementation of agricultural programs in their locality.

During extreme food shortage, most farmers cope by reducing the number of daily meals, and eating some wild fruits "ubuyu" (fruits from Baobab tree), which are common wild fruits in the area. In addition, climate smart agriculture has been adopted by some farmers in the area to adapt to climate impacts. Table 3 shows the existing adaptation measures (mainly climate smart agriculture) in the area, however, the adaptive capacity of each household is based on the level of resource endowments [1]. In this aspect, the poor have a weak capacity to cope compared to the middle and upper classes. These results of the present study are in agreement with Ahmed et al. [4] Below et al. [7], Rowhani et al. [8], Sieber et al. [13], Msongaleli et al. [17], and Cooper and Wheeler [22]. Despite little achievement in these adaptation strategies, much more should be done to improve the situation, as proposed by the respondents themselves in Table 4. They proposed these recommendations to the government because the majority of them had limited knowledge on the agricultural policy, and what has been stipulated in it.

Therefore, farmers' responses can be interpreted as knowledge that needs specific guidance from the governing policy, so that adaptation and mitigation measures can be definite and strong [32-35]. In this case, scientific analyses and climate modeling need to support the creation of farmers' awareness towards the same, otherwise, uncertainties may arise. So far, these uncertainties affect production systems and eventually cause frequent poor yields, food insecurity, and abject poverty in the community.

Besides, the results from meteorological data analyses (Figures 5-7) revealed that there has been a temporal fluctuation and change of both rainfall and temperature. Mean annual and monthly rainfall have been fluctuating at a decreasing trend (Figures 5 and 6), while mean annual and monthly 
temperature have been fluctuating at an increasing trend (Figure 7). The number of wet spells during the growing seasons appeared to have decreased significantly (Figure 6). January (Figure 6a) had a high intensity of fluctuation and decreased significantly compared to February and March as seen in Figure 6b,c.

These results are in agreement with those by Challinor et al. [1], Rowhani et al. [8] and Mkonda [18]. These authors confirmed that the more the wet spells, the higher the yields, and the fewer the wet spells, the more meager the yields. The number of wet spells are perceived by farmers as a good climatic moment, since these wet spells have implications on crop production [4]. In this aspect, we needed to be a bit skeptical because there can numerous wet spells from low rainfall or few wet spells from high rainfall [5]. This is because we mostly look at cumulative rains. According to the analyses of farmers' perception, it was found that at least 10 (i.e., numerous) wet spells that are evenly distributed within a month, have significant impacts to crop production as they provide continued moisture in the soils.

On the other hand, January and March experienced high temperature variations (Figure $7 \mathrm{a}, \mathrm{c}$ ) compared to February (Figure 7b). This had negative implications to crop yields because in most cases, high temperature lowers crop yields and vice versa. This is mostly applied to maize, sorghum, and millet which are not strongly heat resistant crops.

Comparatively, the trends of rainfall in Figures 5 and 6 and temperature presented in Figure 7 are in agreement with other scholars' findings like Paavola [5] and Rowhani et al. [8], who proclaimed that the overall rainfall variability is operating with a decreasing trend, while temperature is increasing. Rowhani et al. [8] further predicted that temperature would increase by $2{ }^{\circ} \mathrm{C}$ and $4{ }^{\circ} \mathrm{C}$ by 2050 and 2100 respectively. He concluded that this trend would exacerbate negative impacts to already stressed human livelihoods and biodiversity. Other supporting scholars with similar observations include Ahmed et al. [4], Rowhani et al. [8], Mongi et al. [10], Mkonda [18], Kangalawe [20], Kangalawe and Lyimo [21], Yanda [28], and Birkmann et al. [29], just to mention a few.

Basing on the two sources of information i.e., farmers' perceptions and meteorological data, we can confidently conclude that rainfall and temperature are changing in Tanzanian. This is because the two sources presented similar results (liaisons). Both showed that rainfall is generally decreasing, especially by observing at drought extremes incidences while temperature is increasing. This reality was proved through field physical observations, as the level of drought in the area was severe. In addition, different models such as Atmosphere-Ocean General Circulation Models (AOGCMs) and CMIP-3 and CMIP-5 have depicted the same trend. Thus, for sustainable adaptation to climate change impacts, we have to validate the information from these two sources and develop an adaptation plan that can increase resilience to the destitute.

While the exact realization of the climate system over the next two decades is unknown, the poverty results from the overall CMIP3 GCM ensemble suggest slightly increasing poverty vulnerability in Tanzania [4]. This is because climate models sometimes indicate less impact, while in actual sense the situation is worse on the ground. This climate-based uncertainty can potentially be resolved by developing the decadal-scale climate prediction techniques [30]. In whole, the determination of climate change should be featured into a sound policy that should stipulate, emphasize and ensure the implementation of climate smart agriculture especially to rural farmers.

However, under some context, there has been a differing perspective between the farmers and the Tanzania Meteorological Agency. In some aspects, the meteorological authorities has been reporting increased rainfall during some years, while the farmers in the fields do not feel the same. In this context, further speculations revealed that the number of drought extremes had outnumbered the wet ones, and thus, having high total rainfall with insignificant impact on farms/production systems. The impacts of this variation has been coupled by the great variability of onset and cessation of rains. This also has been affecting the farming calendar. So far, this has been affecting significantly the poor people who are more vulnerable to the situation $[13,30]$. 
On policy implications; agricultural policy, various agricultural programs and projects have realized that climate impacts have significant effects to crop production. In a country where $70 \%$ of agriculture industry is dominated by smallholder farmers, the improvement of adaptation is strategies is quite pretty. However, the Agricultural Policy (i.e., main agricultural documents) has lightly stipulated climate issues. Therefore, the scientific findings and indigenous/precipitation knowledge should be helpful in amending or improving the related policies.

\section{Conclusions}

Our empirical study is among the first to document the interrelation between meteorological data analyses and farmers' perception in this area. While farmers' perception seem to give clear insights on climate issues, the meteorological data have also provided a clinical climate trend (i.e., increasing temperature and decreasing rainfall) as viewed in global models. Besides, Agricultural and other allied policies have not yet soundly stipulated the same. This reality brings insights to planners, climate project implementers, and all development projects based on the agricultural sector to increase the consideration of scientific findings and community perceptions as they have significant contribution for sustainable adaptation. Basing on existing adaptation strategies (Table 3), it is obvious that intensification of these strategies need not only to be done, but also be stipulated in a robust policy that emphasizes proper and sustainable adaptation strategies (i.e., CSA) to build resilient livelihoods for the farmers.

Acknowledgments: We are indebted to the Chinese Government Scholarship (CSC) for providing the scholarship for Msafiri Y. Mkonda. We also give thanks to Solomon Aunga (from Kenya), the Ph.D. student at the Department of Language and Linguistics, Southwest University in China for editing our manuscript. We also wish to thank research assistants who were involved in data collection. This study is supported by a China Scholar Council International PhD Program to Msafiri Mkonda and the 2015 Chongqing 100 Talents Program to Xinhua He at the Southwest University in Beibei, Chongqing, China". Further, we convey our gratitude thanks to the two anonymous reviewers for their comments and insights on our paper. Their constructive suggestions and inputs remains a permanent assert for reporting similar scientific works in future.

Author Contributions: Both authors designed the study. M.Y.M. collected the data in the study area, analyzed and wrote a first draft. Author X.H. corrected the manuscript to get a final draft for submission. Both authors read and approved the final version for submission.

Conflicts of Interest: The authors declare no conflict of interest.

\section{References}

1. Challinor, A.J.; Wheeler, T.R.; Garforth, C.; Craufurd, P.; Kassam, A. Assessing the vulnerability of food crop systems in Africa to climate change. Clim. Chang. 2007, 83, 381-399. [CrossRef]

2. Challinor, A.J.; Watson, J.; Lobell, D.B.; Howden, S.M.; Smith, D.R.; Chhetri, N. A meta-analysis of crop yield under climate change and adaptation. Nat. Clim. Chang. 2014, 4, 287-291. [CrossRef]

3. Adger, N. Vulnerability. Glob. Environ. Chang. 2006, 268-281. [CrossRef]

4. Ahmed, S.; Deffenbaugh, N.; Hertel, T.; Lobell, D.; Ramankutty, N.; Rios, A.; Rowhani, P. Climate volatility and poverty vulnerability in Tanzania. Glob. Environ. Chang. 2011, 21, 46-55. [CrossRef]

5. Paavola, J. Livelihoods, vulnerability and adaptation to climate change in Morogoro, Tanzania. Environ. Sci. Policy 2008, 11, 642-654. [CrossRef]

6. Intergovernmental Panel on Climate Change (2014a) Climate Change Impacts. Adaptation, and Vulnerability. Part A: Global and Sectoral Aspects. Contribution of Working Group II to the Fifth Assessment Report of the Intergovernmental Panel on Climate Change; Field, C.B., Barros, V.R., Estrada, R.C., Genova, B., Girma, E.S., Kissel, A.N., Levy, S., MacCracken, P.R., Mastrandrea, L.L., Eds.; Cambridge University Press: Cambridge, UK; New York, NY, USA, 2014.

7. Below, T.; Schmid, J.; Sieber, S. Farmers' knowledge and perception of climatic risks and options for climate change adaptation: A case study from two Tanzanian villages. Reg. Environ. Chang. 2015, 15, 1169-1180. [CrossRef]

8. Rowhani, P.; Lobell, D.B.; Linderman, M.; Ramankutty, N. Climate variability and crop production in Tanzania. Agric. For. Meteorol. 2011, 15, 449-460. [CrossRef] 
9. Dessai, S.; Adger, W.N.; Hulme, M.; Turnpenny, J.; Kohler, J.; Warren, R. Defining and experiencing dangerous climate change. Clim. Chang. 2004, 64, 11-25. [CrossRef]

10. Mongi, H.; Majule, A.E.; Lyimo, J.G. Vulnerability Assessment of Rain-fed Agriculture to Climate Change and Variability in Semi-arid areas of Tanzania. Afr. J. Environ. Sci. Technol. 2010, 4, 370-383.

11. Sovacool, B.; Linnér, B.; Klein, R. Climate change adaptation and the Least Developed Countries Fund (LDCF): Qualitative insights from policy implementation in the Asia-Pacific. Clim. Chang. 2017, 140, $209-226$. [CrossRef]

12. IPCC. Managing the risks of extreme events and disasters to advance climate change adaptation. In A Special Report of Working Groups I and II of the Intergovernmental Panel on Climate Change; Field, C.B., Barros, V., Stocker, T.F., Qin, D., Dokken, D.J., Ebi, K.L., Mastrandrea, M.D., Mach, K.J., Plattner, G.-K., Allen, S.K., et al., Eds.; Cambridge University Press: Cambridge, UK, 2012.

13. Sieber, S.; Tscherning, K.; Graef, F.; Sergio, U.; Paloma, G. Food security in the context of climate change and bioenergy production in Tanzania: Methods, tools and applications. Reg. Environ. Chang. 2015, 15, 1163-1168. [CrossRef]

14. Kilembe, C.; Thomas, T.S.; Waithaka, M.; Kyotalimye, M.; Tumbo, S. East African Agriculture and Climate Change: A Comprehensive Analysis-Tanzania; IFPRI: Washington, DC, USA, 2012.

15. Lobell, D.B.; Burke, M.B. On the use of statistical models to predict crop yield responses to climate change. Agric. For. Meteorol. 2010, 150, 1443-1452. [CrossRef]

16. Lobell, D.B.; Burke, M.B.; Tebaldi, C.; Mastrandrea, M.D.; Falcon, W.P.; Naylor, R.L. Prioritizing climate change adaptation needs for food security in 2030. Science 2008, 319, 607-610. [CrossRef] [PubMed]

17. Msongaleli, B.; Rwehumbiza, F.; Tumbo, S.; Kihupi, N. Impacts of Climate Variability and Change on Rainfed Sorghum and Maize: Implications for Food Security Policy in Tanzania. J. Agric. Sci. Can. Cent. Sci. Educ. 2015, 7, 124-142. [CrossRef]

18. Mkonda, M.Y. Rainfall variability and its association to the trends of crop production in Mvomero District, Tanzania. Eur. Sci. J. 2014, 10, 263-273.

19. FAO. Declaration of the world summit on food security. In World Summit on Food Security; FAO: Rome, Italy, 2009; pp. 16-18.

20. Kangalawe, R. Climate change impacts on water resource management and community livelihoods in the southern highlands of Tanzania. Clim. Dev. 2016. [CrossRef]

21. Kangalawe, R.; Lyimo, G. Climate Change, Adaptive Strategies and Rural Livelihoods in Semiarid Tanzania. Nat. Resour. 2013, 4, 266-278. [CrossRef]

22. Cooper, S.J.; Wheeler, T. Rural household vulnerability to climate risk in Uganda. Reg. Environ. Chang. 2017, 17, 649-663. [CrossRef]

23. URT. National Agriculture Policy; Government Publishing Press: Dar es Salaam, Tanzania, 2013.

24. URT. Poverty and Human Development Report; Research and Analysis working Group: Dar es Salaam, Tanzania, 2009.

25. URT. United Republic of Tanzania, National Adaptation Programme of Action (NAPA); Division of Environment, Vice President's Office: Dar es Salaam, Tanzania, 2007.

26. URT. The Agricultural Sector Development Programme; The Agricultural Sector Lead Ministries: Dar es Salaam, Tanzania, 2002.

27. URT. National Environmental Policy; Government Publishing Press: Dar es Salaam, Tanzania, 1997.

28. Yanda, P. Climate Change Implications for Management and Use of Agricultural Biodiversity Resources in Africa. Environ. Ecol. Res. 2015, 3, 35-43. [CrossRef]

29. Birkmann, J.; Cutter, S.L.; Rothman, D.S.; Welle, T.; Garschagen, M.; van Ruijven, B.; O’Neill, B.; Preston, B.L.; Kienberger, S.; Cardona, O.D.; et al. Scenarios for vulnerability: Opportunities and constraints in the context of climate change and disaster risk. Clim. Chang. 2013. [CrossRef]

30. Meehl, G.A.; Goddard, L.; Murphy, J.; Stouffer, R.J.; Boer, G.; Danabasoglu, G.; Dixon, K.; Giorgetta, M.A.; Greene, A.M.; Hawkins, E.; et al. Decadal prediction. Bull. Am. Meteorol. Soc. 2009, 459, 1467-1485. [CrossRef]

31. Kimaro, A.; Mpanda, M.; Rioux, J.; Aynekulu, E.; Shaba, S.; Thiong'o, M.; Mutuo, P.; Abwanda, S. Is conservation agriculture 'climate-smart' for maize farmers in the highlands of Tanzania? Nutr. Cycl. Agroecosyst. 2015, 3, 217-228. [CrossRef] 
32. Speranza, I.; Kiteme, B.; Ambenje, P.; Wiesmann, U.; Makali, S. Indigenous knowledge related to climate variability and change: Insights from droughts in semi-arid areas of former Makueni District, Kenya. Clim. Chang. 2009, 100, 295-315. [CrossRef]

33. Nyong, A.; Francis, A.; Osman-Elasha, B. The value of indigenous knowledge in climate change mitigation and adaptation strategies in the African Sahel. Mitig. Adapt. Strat. Glob. Chang. 2007, 12, 787-797. [CrossRef]

34. Rao, K.; Ndegwa, W.; Kizito, K.; Oyoo, A. Climate Variability and Change: Farmer Perceptions and Understanding of Intra-Seasonal Variability in Rainfall and Associated Risk in Semi-Arid Kenya. Exp. Agric. 2011, 47, 267-291. [CrossRef]

35. Salick, J. Traditional peoples and climate change. Glob. Environ. Chang. 2009, 19, 137-139. [CrossRef]

36. Grothmann, T.; Petzold, M.; Ndaki, P.; Kakembo, V.; Siebenhüner, B.; Kleyer, M.; Yanda, P.; Ndou, N. Vulnerability Assessment in African Villages under Conditions of Land Use and Climate Change: Case Studies from Mkomazi and Keiskamma. Sustainability 2017, 9, 976. [CrossRef]

(C) 2017 by the authors. Licensee MDPI, Basel, Switzerland. This article is an open access article distributed under the terms and conditions of the Creative Commons Attribution (CC BY) license (http://creativecommons.org/licenses/by/4.0/). 